EXTENDED REPORT

\title{
Longitudinal development of skin involvement and reliability of high frequency ultrasound in systemic sclerosis
}

\author{
A Åkesson, R Hesselstrand, A Scheja, M Wildt
}

Ann Rheum Dis 2004;63:791-796. doi: 10.1136/ard.2003.012146

See end of article for authors' affiliations

.....................

Correspondence to:

Dr A Akesson, Department

of Rheumatology, Lund

University Hospital Lund,

22185 Sweden; anita.

akesson@reum.lu.se

Accepted

14 September 2003

\begin{abstract}
Background: Measurement of skin involvement is essential for diagnosis and prognosis in systemic sclerosis. Assessment by palpation skin score is the current method.

Objective: To explore high frequency ultrasound as an objective method to improve skin characterisation by combining measurements of skin thickness and echogenicity.

Methods: Skin thickness and echogenicity were measured at the proximal phalanx of the second digit, the back of the hand, the forearm, and the lower leg and, in order to separate limited (ISSc) from diffuse SSc (dSSc), at the chest in 16 patients with early disease and in 16 controls. Measurements were repeated in each patient three or four times with an interval of 1-2 years. Ultrasound measurements of skin thickness were compared with the palpation skin score.

Results: Compared with controls, the skin was thickened on the phalanx, hand, forearm, and chest of patients with $\mathrm{dSSc}$, but not patients with ISSc, at the 1 year examination. In dSSc the degree of thickening tended to diminish with time, and at 4 years, thickness was significantly decreased on the forearm and chest compared with the 1 year measurements. Low reflectancy was most pronounced at the 1 year evaluation on the forearm, hand, and phalanx in dSSc, and on the phalanx in ISSc.

Conclusion: Separate measurements of skin thickness and echogenicity by high frequency ultrasound add a new dimension to the assessment of skin involvement in SSc, and this seems to be an objective noninvasive tool for use in the study of disease development and in clinical trials.
\end{abstract}

S kin thickening and tightness are characteristic manifestations of systemic sclerosis (SSc, scleroderma) and the only major diagnostic criterion. ${ }^{1}$ The pathophysiology consists of vascular damage, inflammation, and excessive deposition of extracellular matrix by fibroblasts. The extent of skin involvement in early disease permits the diagnostic distinction between limited (ISSc) and diffuse SSc (dSSc). ${ }^{2}$ Three phases of skin involvement can be identified: an early oedematous phase associated with increased amounts of interstitial fluid, an indurative phase during which newly synthesised collagen is deposited in the skin, and an atrophic phase in which thinning of the abnormal skin may occur. ${ }^{3}$

In 1979 Rodnan introduced the semiquantitative scoring technique of skin palpation to characterise and quantify skin involvement in SSc. ${ }^{4}$ It is today in general use with minor modifications, ${ }^{5-8}$ despite the shortcomings of observer varia$\operatorname{tion}^{78}$ and inability to distinguish between the features skin thickness and tightness. In 1979 Alexander and Miller introduced a new non-invasive method for measurement of skin thickness by $15 \mathrm{MHz}$ ultrasound. ${ }^{9}$ The determination of skin thickness with $10-15 \mathrm{MHz}$ is a reproducible method, ${ }^{10}{ }^{11}$ but requires easily identifiable interfaces. High frequency $(20 \mathrm{MHz})$ ultrasound offers considerably better resolution, which makes it possible to distinguish dermis from subcutaneous fat, and to measure skin thickness regardless of the underlying tissue. The development of very high frequency, high resolution equipment has made cross sectional (two dimensional) images possible, ${ }^{12}$ which not only allow the determination of skin thickness but also a qualitative assessment of the skin composition. Dermal echoes are in most body regions many and variable. They originate from the well organised fibre network, which is also responsible for the tensile properties of the skin. Conditions, which compromise this network, cause low echogenicity and reflect, for example, subepidermal increase of interstitial fluid in oedema. ${ }^{13}$ High frequency ultrasound has been used in several skin diseases ${ }^{14}$ but only in limited amounts in localised ${ }^{15}$ and systemic scleroderma. ${ }^{16-19}$ This report examines the performance of a standardised high frequency ultrasound protocol in longitudinal observations of patients with early phases of both types of SSc. The results were compared with the Rodnan score and with ultrasound measurements in healthy controls.

\section{PATIENTS AND METHODS}

\section{Patients}

Sixteen patients, who all fulfilled the American College of Rheumatology criteria for the classification of scleroderma, ${ }^{1}$ and 16 controls were selected for the study. The controls comprised sex matched healthy subjects randomly selected from the Swedish population register. Eight patients had skin thickening restricted to the extremities and face (ISSc) and eight also had skin sclerosis on the trunk (dSSc). ${ }^{2}$ Disease duration, defined from the beginning of skin involvement, was 1 year or less in 13 patients or 2 years or less in three patients. Table 1 shows the demographic features of patients and controls.

\section{Ultrasound}

Skin thickness and echogenicity were measured with a high frequency ultrasound scanner (Dermascan, Cortex Technology, Denmark), in which a $20 \mathrm{MHz}$ transducer was mounted in a water chamber. The chamber window was covered with a disposable plastic membrane. A conductive gel was used to ensure satisfactory contact between the crystal face and the skin. The transducer was placed perpendicular to the skin. Two scans were obtained of the tissue: a one dimensional A mode image with different echoes defining the interfaces between epidermis, dermis, and subcutis, and a two dimensional $\mathrm{B}$ mode image with different colours reflecting the differing echogenicities of the skin (fig 1). The quality criterion adopted for acceptance of an ultrasound 
Table 1 Demographic features of patients with SSc and of controls

\begin{tabular}{llll}
\hline & \multicolumn{2}{l}{ Systemic sclerosis } & \\
\cline { 2 - 3 } & Diffuse & Limited & Controls \\
\hline Number (female) & $8(7)$ & $8(7)$ & $16(8)$ \\
Age (years) & $45(26-67)^{*}$ & $52(33-68)^{*}$ & $44(27-70)^{*}$ \\
Duration $\leqslant 1$ year & 8 & 5 & \\
Duration $\leqslant 2$ years & & 3 & \\
TSS (points) & $27(12-32)$ & $7(4-19)$ & \\
Anti-topoisomerase-1 & 4 & 1 & \\
ACA & 1 & 4 & \\
\hline
\end{tabular}

${ }^{*}$ Median (range).

TSS, total skin score; ACA, anticentromere antibody.

image was the reproduction of echoes, which defined the interfaces between the epidermis, dermis, and subcutis by the A mode, and a correlated B mode image, which showed the echogenicity of the epidermis, dermis, and subcutis. The measurement was made at a site in the B mode image where the demarcation lines between the epidermis, dermis, and subcutis were parallel, and the echoes of the corresponding A mode image distinct. The echogenicity in the dermal region was represented on an arbitrary scale (0-255 pixels), and by outlining a block of skin the mean echogenicity was estimated for a selected region ${ }^{12}{ }^{16}$ The measurements of skin thickness and echogenicity which are given in the results stand for the epidermis plus dermis.

All measurements were made before noon. The measuring points were selected in order to distinguish skin involvement in ISSc and dSSc, and to monitor disease development over time. Measurements were made at each of five skin sitesover the dorsal aspect of the interarticular portion of the proximal phalanx of the right second finger (phalanx), over the area (valley) between the metacarpophalangeal joints II and III of the right hand (hand), over the dorsal aspect of the right forearm $3 \mathrm{~cm}$ proximal of the wrist (forearm), over the lateral aspect of the leg $12 \mathrm{~cm}$ proximal of the ankle joint (leg), and over the sternum $2 \mathrm{~cm}$ distal from the upper part of the manubrium (chest) —and repeated in each patient three or four times with an interval of $1-2$ years.

\section{Skin score}

Skin involvement was determined by palpation of 17 anatomical sites (face, fingers, hands, forearms, upper arms, chest, abdomen, thighs, legs, and feet) and scoring on a 0-3
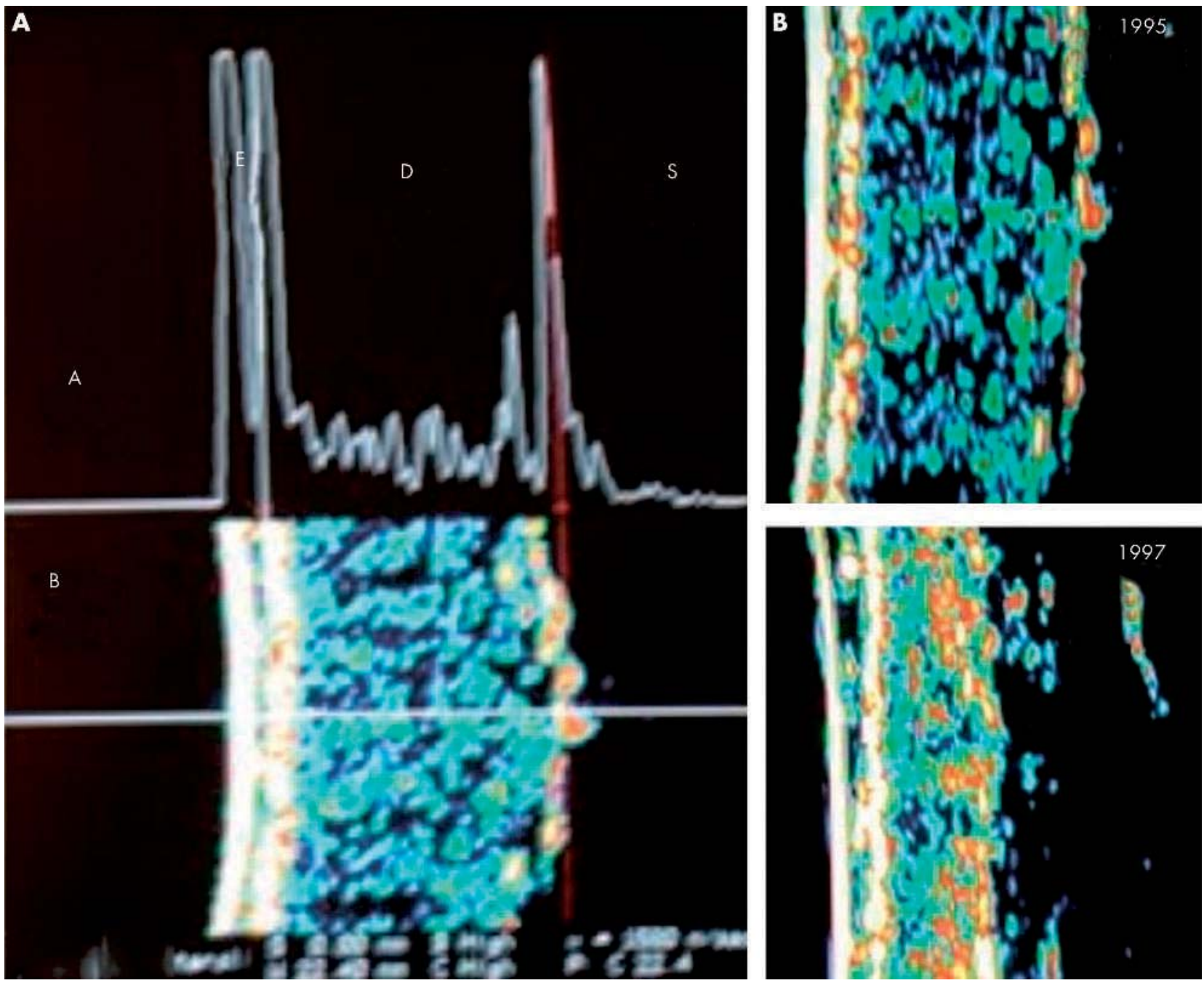

Figure 1 (A) Skin thickness and echogenicity by high frequency ultrasound. A, A mode image of the forearm skin. Echoes defining the epidermis (E), dermis (D), and subcutis (S) are marked. B, B mode image of the forearm skin with the epidermis, dermis, and subcutis. (B) Skin thickness and echogenicity in a patient with dSSc. At 1 year's disease duration skin thickness was $2.5 \mathrm{~mm}$ and skin echogenicity 16 pixels. Two years later skin thickness had decreased to $1.3 \mathrm{~mm}$, while skin echogenicity had increased to 36 pixels. 


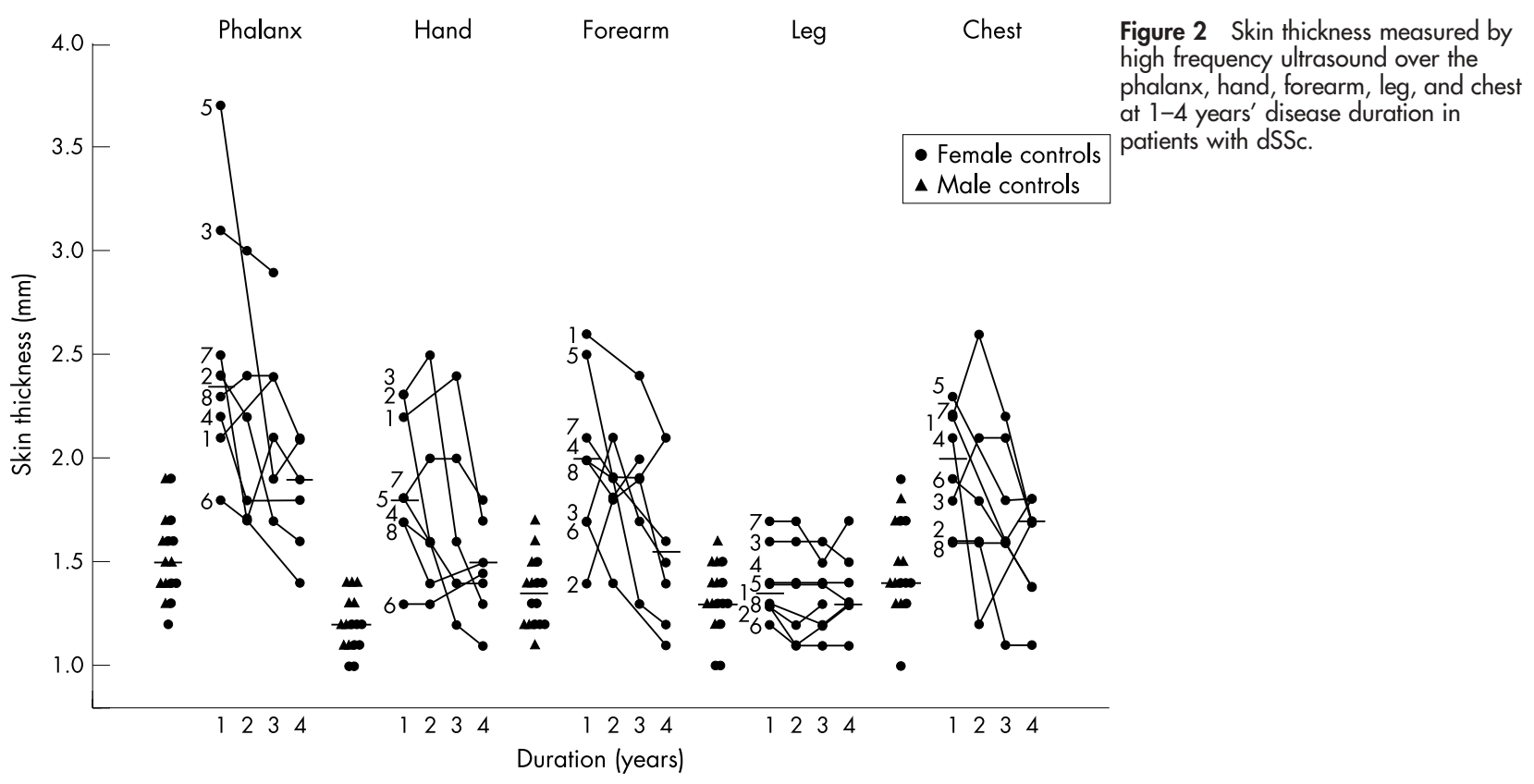

scale, where $0=$ normal skin, $1=$ slight thickening, $2=$ moderate thickening, and $3=$ hidebound skin sclerosis. The scores for all sites were summed to give a total score, with a maximum possible score of 51 . The palpation was performed by one of two assessors (AS/A $\AA$ ), both well trained in skin palpation and unaware of the result of the ultrasound assessment of the patient.

\section{Immunological analyses}

Anti-topoisomerase I antibody positivity (scleroderma-70 antibody) was detected by immunodiffusion, and anticentromere antibody positivity by immunofluorescence using an HEp-2 substrate (performed by the Department of Clinical Immunology, University Hospital, Lund, Sweden).

\section{Statistics}

The significance of differences between patients and controls was calculated with one way analysis of variance, followed by multiple comparisons using Tukey's method. Associations between ultrasound measurements and skin scores were calculated with the Pearson correlation test.

Reproducibility was measured by the mean of the absolute differences between the observers and intraclass correlations (ICC). The measurements were derived from the first visit of the patients and from all controls. All measurements were performed before noon by two trained observers (MW and AA), who each obtained two ultrasound images of all investigated areas. Both observers measured thickness and echogenicity of all four images (table 2). Interobserver and intraobserver variability were calculated for both $\mathrm{MW}$ and $\mathrm{A} \AA$ with the same results. Intraobserver variability of ultrasound measurements in table 3 are calculated from measurements by MW, who measured thickness and echogenicity of all pictures at two different occasions, and interobserver variability by $\mathrm{MW}$ and $\mathrm{A} \AA$, who independently measured the thickness and echogenicity of every image.

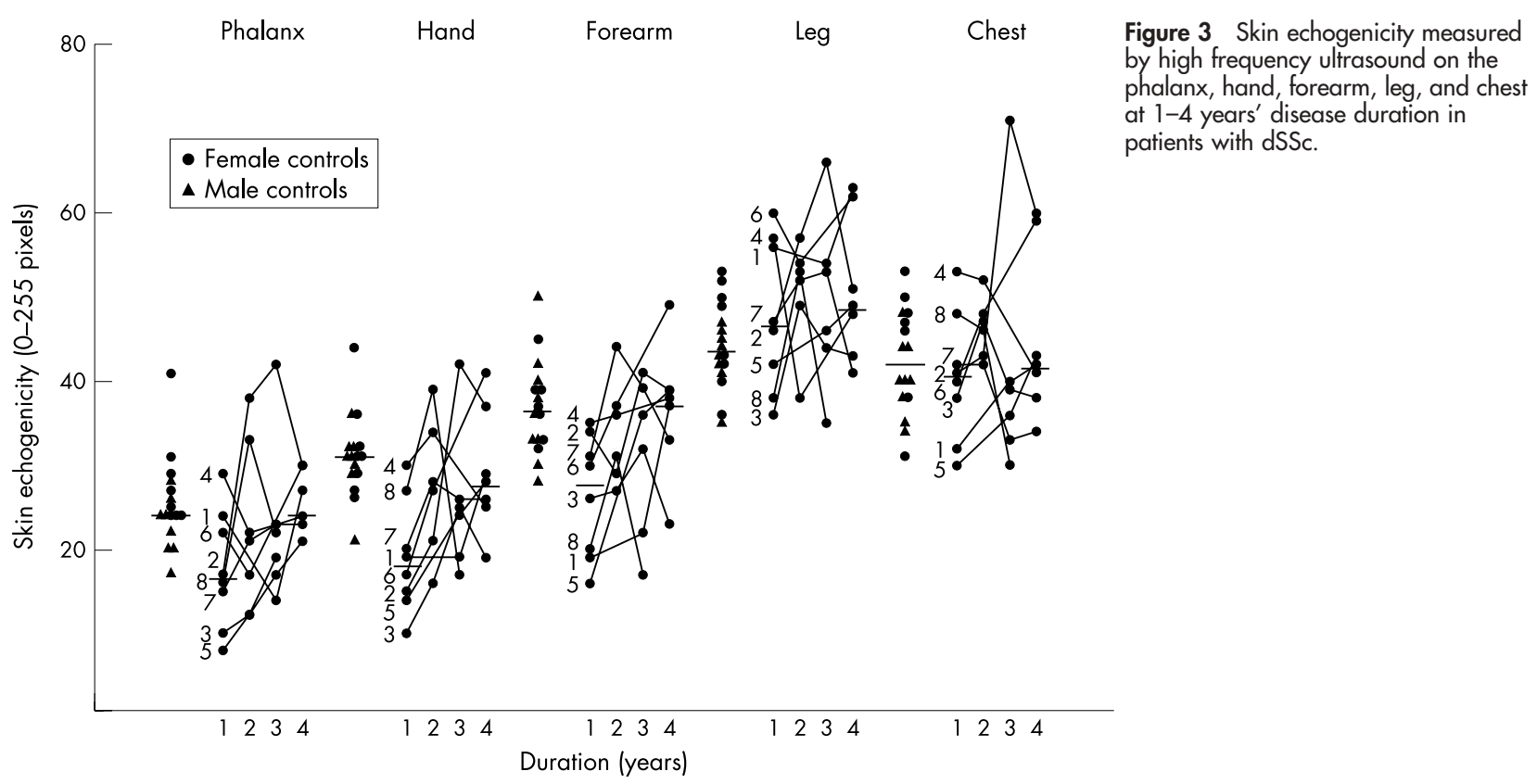


Table 2 Skin thickness and echogenicity in patients with SSc and controls at the 1 year measurements

\begin{tabular}{|c|c|c|c|c|}
\hline & \multicolumn{2}{|c|}{ Systemic sclerosis } & \multirow[b]{2}{*}{ Controls } & \multirow{2}{*}{$\begin{array}{l}\text { Differences between } \\
\text { dSSc and ISSc } \\
\text { (p value) }\end{array}$} \\
\hline & Diffuse & Limited & & \\
\hline \multicolumn{5}{|l|}{ Thickness } \\
\hline Phalanx & $2.5(0.6)^{* \star *}$ & $1.9(0.3)$ & $1.5(0.2)$ & 0.02 \\
\hline Hand & $1.9(0.4)^{\star \star \star *}$ & $1.4(0.4)$ & $1.2(0.1)$ & 0.02 \\
\hline Forearm & $2.0(0.4)^{\star \star \star *}$ & $1.5(0.2)$ & $1.3(0.2)$ & $<0.01$ \\
\hline Leg & $1.4(0.2)$ & $1.3(0.2)$ & $1.3(0.2)$ & NS \\
\hline Chest & $2.0(0.3)^{\star * *}$ & $1.5(0.2)$ & $1.5(0.2)$ & $<0.01$ \\
\hline \multicolumn{5}{|l|}{ Echogenicity } \\
\hline Phalanx & $17.5(7.1)^{* *}$ & $19.3(6.0)^{*}$ & $27.3(6.0)$ & NS \\
\hline Hand & $18.9(6.7)^{* *}$ & $28.0(13.6)$ & $31.8(5.3)$ & NS \\
\hline Forearm & $26.4(7.2)^{\star *}$ & $39.8(9.8)$ & $37.6(5.6)$ & $<0.01$ \\
\hline Leg & $47.8(9.0)$ & $50.2(6.4)$ & $44.0(5.5)$ & NS \\
\hline Chest & $40.5(7.6)$ & $47.6(7.0)$ & $42.5(6)$ & NS \\
\hline
\end{tabular}

${ }^{*}$ Significantly different from controls $p<0.05 ;{ }^{* *} p<0.01 ;{ }^{* * *} p<0.001$.

Results are shown as mean (SD).

\section{RESULTS}

At the first evaluation the skin was thicker than that of the controls on the phalanx, hand, forearm, and chest in patients with dSSc, while synchronous measurements showed decreased echogenicity of the phalanx, hand, and forearm skin (table 2). Compared with the first evaluation, repeated measurements at 2-4 years showed diminished skin thickness in most patients, and after 4 years the skin on the forearm and chest was significantly decreased ( $p<0.05$, fig 2 ). Skin echogenicity also changed, but was significantly increased after 4 years only on the skin of the hand $(\mathrm{p}<0.05$, fig 3$)$.

Figure 4 shows serial measurements of skin thickness and skin echogenicity in a patient with dSSc. At l year skin thickness on the phalanx and hand was above the normal range, concurrent with a low skin echogenicity. Compared with the 1 year evaluation measurements, increasing echogenicity was seen at 2 and 3 years in all areas except the forearm. At the 4 year evaluation skin thickness was normal or decreased in all areas, concurrent with a decrease in skin echogenicity

Most patients with ISSc had thickened skin on the phalanx and hand throughout the study (table 2, fig 5), while skin echogenicity on the phalanx was decreased compared with controls at the first evaluation (table 2, fig 6).

Table 3 outlines reliability data of the ultrasound measurements. Although both the interobserver and intraobserver reliability varied depending on the anatomical site, the results indicate that the precision of measurements of skin thickness and echogenicity is reproducible between technicians (MW/ $\mathrm{A} \AA$ ) and within technicians (MW). Measurements of skin thickness and echogenicity were not related to regional skin scores in patients with dSSc, except for skin echogenicity of the hand $(\mathrm{p}<0.01)$ at the 3 year evaluation. In patients with ISSc skin thickness was related to the regional score of the hand $(\mathrm{p}<0.05)$ at the 2 year measurement, to regional scores of the phalanx and hand $(\mathrm{p}<0.01)$ at 3 years, and to scores of the forearm $(p=0.02)$ and chest $(p<0.001)$ at 4 years.

The controls were not followed up. It has been presumed that a number of variables-namely, race, age, sex, anatomical site, and time of the day may be relevant for the outcome of measurements of skin thickness. Although the number of patients was small, no differences of age were found for either thickness or echogenicity among the controls. This is accordance with results by de Rigal and coworkers, ${ }^{20}$ who by ultrasound imaging observed a phase of maturation up to 15 years of age, after which skin thickness did not vary significantly until after the seventh decade. Nor did the present study show differences in thickness and echogenicity between male and female controls (figs 2-5). On the contrary, table 2 shows differences due to anatomical site both with respect to thickness and echogenicity.

\section{DISCUSSION}

Skin involvement in scleroderma reflects internal organ pathology. The extent of early skin involvement distinguishes the two major forms of SSc and correlates with prognosis. ${ }^{21}$ Therefore there is a need for a reliable technique not only to assess the extent and degree of skin thickening but also to recognise different stages of the disease.

The Rodnan skin score ${ }^{4}$ and its modifications $s^{5-8}$ employs a qualitative rating scale of skin changes on palpation of multiple body areas, and is a semiquantitative tool validated for clinical assessment and research. A relationship exists between the weight of a forearm skin biopsy and both regional ${ }^{3}$ and total thickness score, ${ }^{22}$ but interestingly not with a skin oedema score..$^{22}$ This illustrates the limitations of clinical palpation to distinguish different stages of the disease.

The emergence of high frequency ultrasound technology has made cross sectional images possible, which allow not only precise measurement of skin thickness but also qualitative assessment of the skin in vivo. The temporal development of truncal involvement has not been investigated in detail, despite its importance for distinction between the subsets. Skin, which appears to be unaffected among patients with scleroderma, might nevertheless be abnormal. Despite absence of skin changes by palpation and histological examination Ihn et al reported significantly increased thickness by ultrasound of both clinically affected and unaffected skin in patients with SSc compared with controls. ${ }^{17}$ This discrepancy might be due to the inability to recognise oedema by palpation, and to loss in skin thickness at biopsy.

By high frequency ultrasound it seems possible to detect different stages of the disease in different investigated areas. This is exemplified in fig 4, which shows serial measurements of skin thickness and echogenicity in a patient with dSSc. At the first evaluation skin thickness on the phalanx and hand is higher than normal, while skin echogenicity is lower than normal. Because an increase in interstitial fluid is a known cause of low reflectancy, ${ }^{13}$ the thickening might be due to oedema in these areas. Compared with the 1 year evaluation, measurements at 2 and 3 years show increased echogenicity in all areas except the forearm. This may be due to 
- Skin score

- Skin thickness

A Skin echogenicity

Skin thickness of controls (SD)

Skin echogenicity of controls (SD)
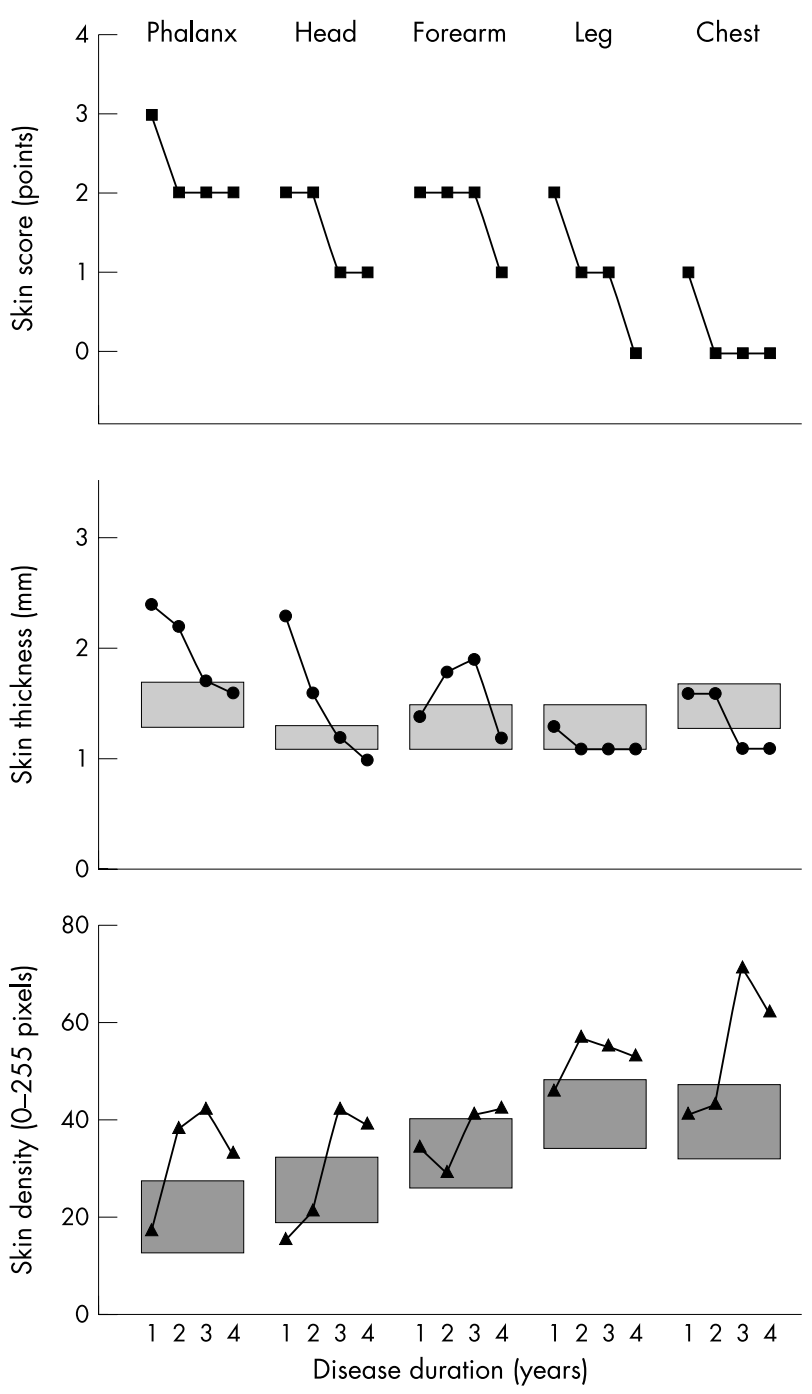

Figure 4 Skin thickness assessed by clinical palpation with rating on a $0-3$ scale (where $0=$ normal skin, $1=$ slight thickening, $2=$ moderate thickening, $3=$ thickened immobile skin) and measurements of skin thickness and echogenicity by high frequency ultrasound at 1-4 years disease duration in a patient with $\mathrm{dSS}$.

replacement of interstitial fluid by newly synthesised collagen in these locations, ${ }^{23}$ and a change of skin involvement from the oedematous to the indurative stage of the disease. At the 4 year evaluation, skin thickness is normalised or decreased in all areas, concurrent with a decrease in skin echogenicity, which might indicate that the overproduction of matrix components has regressed.

In the present study this is further illustrated by repeated measurements of skin thickness and echogenicity in patients with dSSc, who at the first evaluation had skin echogenicity on the chest which was not different from controls, while skin thickness on the same area was increased (table 2). This might indicate that the chest skin has already reached the indurative stage, while decreased echogenicity and increased thickness of other investigated areas points to a continuous oedematous phase of the disease.

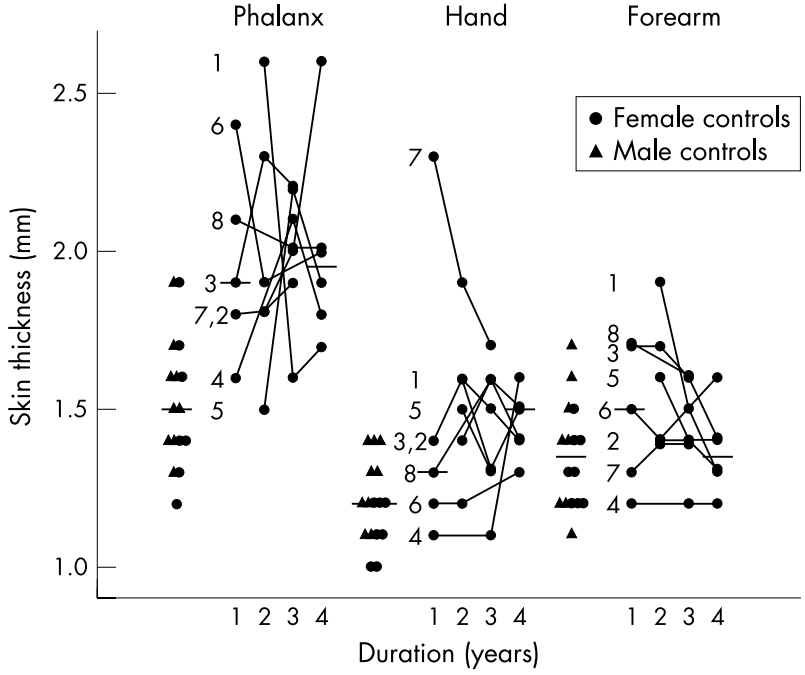

Figure 5 Skin thickness measured by high frequency ultrasound on the phalanx, hand, and forearm at 1-4 years' disease duration in patients with ISSc.

Clinical palpation may not detect skin thickness but rather changes of skin texture, which might be due to either increased amounts of interstitial water or matrix components. This may explain the absence of association between the skin score and ultrasound measurement in most locations investigated, and is concordant with comparisons between skin scoring and durometer readings. ${ }^{24}$

The reliability of the ultrasound technique allows recognition of small and serial changes in the extent and nature of skin involvement. Although the number of patients is small it seems possible to visualise the transition from an oedematous to an indurative phase by combining measurements of skin thickness and skin echogenicity and thus facilitate estimation of the disease stage. This may be important in characterisation of the natural course of the disease and in clinical studies, which has been shown in morphoea, ${ }^{25}$ but not yet in SSc.

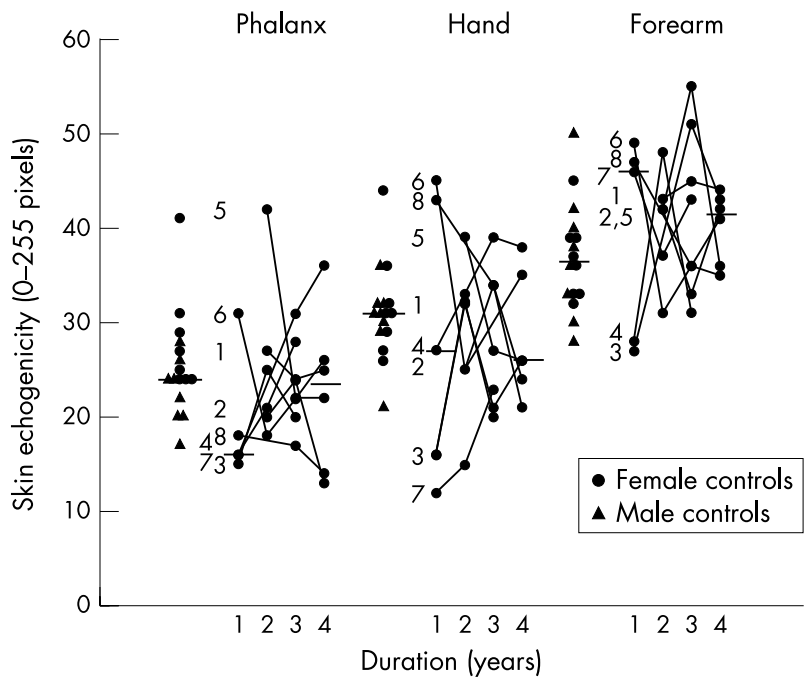

Figure 6 Skin echogenicity measured by high frequency ultrasound on the phalanx, hand, and forearm at 1-4 years' disease duration in patients with ISSc. 
Table 3 Reliability data of ultrasound measurements

\begin{tabular}{|c|c|c|c|c|c|c|c|c|}
\hline & \multicolumn{4}{|c|}{ Interobserver variation } & \multicolumn{4}{|c|}{ Intraobserver variation } \\
\hline & \multicolumn{2}{|c|}{ Thickness } & \multicolumn{2}{|c|}{ Echogenicity } & \multicolumn{2}{|c|}{ Thickness } & \multicolumn{2}{|c|}{ Echogenicity } \\
\hline & $\begin{array}{l}\text { Mean } \\
(\mathrm{mm})\end{array}$ & ICC & $\begin{array}{l}\text { Mean } \\
\text { (pixel) }\end{array}$ & ICC & $\begin{array}{l}\text { Mean } \\
(\mathrm{mm})\end{array}$ & ICC & $\begin{array}{l}\text { Mean } \\
\text { (pixel) }\end{array}$ & ICC \\
\hline Phalanx & 0.15 & 0.66 & 1.3 & 0.98 & 0.05 & 0.95 & 2.6 & 0.83 \\
\hline Hand & 0.06 & 0.83 & 1.1 & 0.97 & 0.04 & 0.92 & 2.7 & 0.81 \\
\hline Forearm & 0.08 & 0.83 & 0.6 & 0.99 & 0.05 & 0.96 & 2.4 & 0.88 \\
\hline Leg & 0.07 & 0.88 & 1.4 & 0.92 & 0.03 & 0.97 & 2.7 & 0.82 \\
\hline Chest & 0.10 & 0.84 & 0.8 & 0.99 & 0.04 & 0.98 & 2.7 & 0.87 \\
\hline
\end{tabular}

\section{Authors' affiliations}

A Akesson, R Hesselstrand, A Scheja, M Wildt, Department of

Rheumatology, Lund University Hospital Lund, Sweden

\section{REFERENCES}

1 ARA. Subcommittee for Scleroderma Criteria of the American Rheumatism Association Diagnostic and Therapeutic Criteria Committee: preliminary criteria for the classification of systemic sclerosis (scleroderma). Arthritis Rheum 1980;23:581-90.

2 Leroy EC, Black C, Fleischmajer R, Jablonska S, Krieg T, Medsger TA Jr, et al. Scleroderma (systemic sclerosis): classification, subsets and pathogenesis. J Rheumatol 1988;15:202-5.

3 Rodnan GP, Lipinski E, Luksick J. Skin thickness and collagen contents in progressive systemic sclerosis and localised scleroderma. Arthritis Rheum 1979;22:130-40.

4 Steen VD, Medsger TA Jr, Rodnan GP. D-Penicillamine therapy in progressive systemic sclerosis (scleroderma). A retrospective analysis. Ann Intern Med 1982;97:652-9.

5 Kahaleh MB, Sultany GL, Smith EA, Huffstutter JE, Loadholt CB, LeRoy EC. A modified scleroderma skin scoring method. Clin Exp Rheumatol 1986;4:367-9.

6 Clements PJ, Lachenbruch PA, Ng SC, Simmons M, Sterz M, Furst DE. Skin score. A semiquantitative measure of cutaneous involvement that improves prediction of prognosis in systemic sclerosis. Arthritis Rheum 1990;33:1256-63.

7 Brennan P, Silman A, Black C, Bernstein R, Coppock J, Maddison P, et al. Reliability of skin involvement measures in scleroderma. $\mathrm{Br} J$ Rheumatol 1992:31:457-60.

8 Clements P, Lachenbruch P, Siebold J, White B, Weiner S, Martin R, et al. Inter and intraobserver variability of total skin thickness score (modified Rodnan TSS) in systemic sclerosis. J Rheumatol 1995;22:1281-5.

9 Alexander H, Miller DL. Determining skin thickness with pulsed ultrasound. J Invest Dermatol 1979;72:17-19.

10 Tan CY, Statham B, Marks R, Payne PA. Skin thickness measurement by pulsed ultrasound: its reproducibility, validation, and variability. Br J Dermatol 1982;106:657-67.

11 Åkesson A, Forsberg L, Hederström E, Wollheim FA. Ultrasound examination of skin thickness in patients with progressive systemic sclerosis (scleroderma). Acta Rad Diagn 1986;27:91-4.

12 Serup J. Ten years' experience with high-frequency ultrasound examination of the skin: development and refinement of technique and equipment. In:
Altmeyer P, ed. Ultrasound in dermatology. Berlin: Springer, 1992:41-54. (ISBN 3-540-53750-3).

13 Gniadecka M, Quistorff B. Assessment of dermal water by high-frequency ultrasound: comparative studies with nuclear magnetic resonance. Br J Dermatol 1996; 135:218-24.

14 Fornage B, McGavran M, Duvic M, Waldron C. Imaging of the skin with 20MHz US. Radiology 1993;189:69-76.

15 Hoffman K, Gerbaulet U, EL-Gammal S, Altmeyer P. 20-MHz B-mode ultrasound in monitoring the course of localized scleroderma (morphea). Acta Derm Venereol (Stockh) 1991;(suppl 164):3-16.

16 Scheja A, Åkesson A. Comparison of high frequency $(20 \mathrm{MHz})$ ultrasound and palpation for the assessment of skin involvement in systemic sclerosis (scleroderma). Clin Exp Rheumatol 1997;15:283-8.

17 Ihn H, Shimozuma M, Fujimoto M, Sato S, Kikuchi K, Igarashi A, et al Ultrasound measurement of skin thickness in systemic sclerosis. Br J Rheumatol 1995; 34:535-8.

18 Seidenari S, Belletti B, Conti A. A quantitative description of echographic images of sclerotic skin in patients with systemic sclerosis as assessed by computerized image analysis on $20 \mathrm{MHz}$ B-scan recordings. Acta Derm Venereol 1996;76:361-4.

19 Brocks K, Stender I, Karlsmark T, Ullman S, Halberg P, Jacobsen S. Ultrasonic measurement of skin thickness in patients with systemic sclerosis. Acta Derm Venereol 2000;80:59-60.

20 de Rigal J, Escoffier C, Querleux B, Faivre B, Agache P, Lévêque J-L. Assessment of aging of the human skin by in vivo ultrasonic imaging. $J$ Invest Dermatol 1989:93:621-5.

21 Clements PJ, Hurwitz EL, Wong WK, Seibold JR, Mayes M, White B, et al. Skin thickness score as a predictor and correlate of outcome in systemic sclerosis. Arthritis Rheum 2000;43:2445-54

22 Furst DE, Clements PJ, Steen VD, Medsger TA Jr, Masi AT, Dángelo WA, et al. The modified Rodnan skin score is an accurate reflection of skin biopsy thickness in systemic sclerosis. J Rheumatol 1998;25:84-8.

23 Hesselstrand R, Westergren-Thorsson G, Scheja A, Wildt M, Åkesson A. The association between changes in skin echogenicity and the fibroblast production of biglycan and versican in systemic sclerosis. Clin Exp Rheumatol 2002;20:301-8.

24 Merkel PA, Gelbard RB, Anderson JJ, Kaluta A, Kissin EY, Simms RW, et al. Reliability and utility of durometer measurements of skin hardness for scleroderma [abstract]. Arthritis Rheum 2002;(suppl):S174.

25 Szymanska E, Nowicki A, Mlosek K, Litniewski J, Lewandowski M, Secomski W, et al. Skin imaging with high frequency ultrasound - preliminary results. Eur J Ultrasound 2000;12:9-16. 